\title{
Territorios culturales: un análisis comparativo de las características de la información periodística en la contemporaneidad
}

\author{
Carla Reis LONGHI \\ Pontifícia Universidade Católica de São Paulo - PUC/SP (Brasil) \\ Universidade Paulista - UNIP/SP (Brasil) \\ carlalonghi@uol.com.br
}

Recibido: 20 de febrero de 2015

Aceptado: 9 de marzo de 2016

\section{Resumen}

En este artículo proponemos la reflexión sobre la información periodística en el contexto contemporáneo a partir del análisis de las características del soporte del periódico, en una comparación entre dos periódicos de distintos países. A partir de los conceptos de espacialidad, visualidad y comunicabilidad, discutidos por Ferrara, considerando también el análisis de los componentes de paginación y diagramación de los periódicos, buscamos escudriñar los sentidos de la información y del conocimiento en este contexto de instrumentalización técnica.

Palabras clave: información periodística; noticia y publicidad; espacialidad mediática.

\section{Cultural territories: a comparative analysis of the characteristics of journalistic information in contemporaneity}

\begin{abstract}
This paper proposes a reflection on the journalistic information in the contemporary context through the analysis of newspaper carrier features printed on a comparative analysis of two newspapers from different countries. Based on the concepts of spatiality, visuality and communicability, discussed by Ferrara, considering the analysis of paging components and layout of newspapers, we seek to unravel the meanings of information and knowledge in this technique exploitation context.

Keywords: journalistic information; news and advertising; spatiality media.

\section{Referencia normalizada}

LONGHI, Carla Reis (2016): "Territorios culturales: un análisis comparativo de las características de la información periodística en la contemporaneidad". Estudios sobre el Mensaje Periodístico. Vol. 22, Núm. 1 (enero-junio), págs.: 411-430. Madrid, Ediciones Complutense.
\end{abstract}

Sumario: 1 . Introducción y objetivos; 2 . Hipótesis; 3 . Metodología; 4 . Territorios Culturales: entre colecionamentos y descolecionamentos; 5. Comunicabilidad e instrumentalización técnica. 6 . Referencias bibliográficas. 7. Hemerografía.

\section{Introducción y objetivos}

Cuando tomamos el periódico como objeto de investigación, inevitablemente nos encontramos con su contenido central, la noticia, y con su función primaria - la información. Esos dos aspectos, individualmente y relacionados, ya suscitan una problemática, tanto en relación al sentido diseminado contemporáneamente sobre sus términos, cuanto en relación al papel asumido por el periodismo de acuerdo con los sentidos incorporados. Considerar el papel social del periodismo implica comprender sus funciones y sentidos históricamente puestos. Sin pretender hacer un recorrido histórico/diacrónico del periodismo desde su nacimiento, podemos verificar rápidamente algunos de los ejes clarificadores, para después considerarlo en su contemporaneidad. 
Muchos autores ya reconstituyeron este proceso, estableciendo recortes explicativos propios. Habermas (1984), al retornar al origen del periódico, señala dos grandes momentos definidores del papel de la prensa hasta el inicio del siglo XIX: vislumbra la caracterización de la prensa desde sus principios, inicio del siglo XVII hasta el inicio del sigo XVIII claramente vinculada a la función de noticiar informaciones. Los periódicos nacieron, esencialmente, como organizadores de la actividad comercial de la burguesía, también naciente; así, servían como forma de registro de actividades económicas, principalmente del comercio internacional, garantizando no solo la publicitación de la actividad comercial, como también, el registro y efectuación contractual de las mismas. El siglo XVIII traza un cambio de sentido. "Los periódicos pasaron de simples instituciones publicadoras de noticias para, además, ser portavoces y conductores de la opinión pública, medios de luchas partidarias" (Habermas, 1984: 214). Como acentúa el autor, la constitución de una esfera pública literaria, iniciada justamente por el periódico, fue fundamental para la constitución de una sociabilidad burguesa frente al predominio noble que había hasta entonces. Esta situación fue propia de este siglo donde "[...] la costumbre constituye la retórica de legitimación de casi todo el uso, práctica o derecho reclamado. Por esto, la costumbre no codificada - y hasta mismo la codificada - estaba en flujo continuo" (Thompson, 1998: 16). En este momento, los periodistas se pautaban por el texto de opinión, de carácter retórico, con finalidad persuasiva. Es interesante notar que los presupuestos de la objetividad e imparcialidad no eran aún una premisa del periodismo, es decir, las premisas que nortean el hacer periodístico también son definidas históricamente y deben ser pensadas y consideradas en el escenario que son utilizadas. El siglo XIX establece los parámetros que van a marcar el hacer periodístico reconocido por nosotros.

Encontraremos, a partir de este siglo, una construcción más multifacética cuanto a la característica del texto periodístico. Por un lado, proliferan periódicos de naturaleza sensacionalista y/o caracterizados como folletines, atendiendo a matrices culturales de los nuevos lectores ${ }^{1}, \mathrm{y}$, de otro lado, se busca la fundamentación de premisas que diferencien los periódicos no sensacionalistas. Como indica Traquina (2005), las técnicas pasan a ser desarrolladas para la mejora de la función, como recurso de descripción (de personas y lugares); el uso de múltiples fuentes para fundamentar el texto; el nacimiento del periodismo investigativo; la utilización del reportaje, entre otros. Estas diferencias y especificidades alteran la configuración del soporte, el contenido y las características de la narrativa de los textos. Va a ser en este escenario que el entendimiento sobre el texto periodístico se concretizará como constituido a partir de la noticia, siendo ésta definida como "el texto básico del periodismo es la noticia, que expone un hecho nuevo o desconocido, o una serie de hechos nuevos o desconocidos del mismo evento, con sus circunstancias" (Lage, 2005: 73). Retomando la idea de que estos términos/conceptos/sentidos son históricamente puestos proponemos, en esta investigación, reflexionar sobre las características de la información periodística en la contemporaneidad. Partimos del presupuesto que las condiciones de producción de la

1 Sobre el folletín y su matriz cultural, observar Martin-Barbero en 'Dos Meios às Mediações'. 
información están, hoy, mediadas por la técnica, cambiando sus características y lógicas de constitución. Centrémonos, en este artículo, en el análisis de las relaciones constituidas entre la espacialidad, la visualidad y la comunicabilidad del periódico y su impacto en la constitución de la información periodística. Para tal, establecemos un análisis comparativo entre periódicos de dos países, Brasil y España ${ }^{2}$. Buscamos identificar las características de la diagramación y paginación en los periódicos de los dos países; la relación establecida entre la información periodística y la publicidad; las características de visualidad y los resultados de la composición entre el espacio de diagramación y el espacio comunicante del periódico para la caracterización de la información periodística.

Varios autores están discutiendo sobre el sentido conceptual contemporáneo de términos como información y noticia, información periodística y conocimiento y sus interconexiones (Traquina, Medistch, Romano, França, entre otros) y, notablemente, no hay un consenso sobre estas discusiones. A partir de la idea indicada por Lage, sin necesariamente coincidir con ella, de que "el que caracteriza el texto periodístico es el volumen de información factual. Resultado de verificación y tratamiento de datos, pretende informar, no convencer" (Lage, 2005: 73) proponemos la reflexión sobre estas cuestiones, participando de este debate a partir del estudio de caso propuesto. Partimos del sentido etimológico del término información:

El sustantivo informatio se deriva del verbo informare, que, como puede verse fácilmente, se compone de "in" y "forma", esto es, formar en, dar forma a algo. De ahí que los significados de "informar" sean: formar, configurar, dar forma a la materia, esculpir, dibujar una imagen, presentar, describir, enseñar, educar, capacitar a alguien para algo.

Así que "información" significa nada más y nada menos que "formación", "configuración", "educación", tanto en sentido literal como figurado. En sentido literal significa proveer a algo de forma, y en sentido figurado a lo que hoy denominamos con las palabras formación o educación.

En este último sentido entendemos "Información" como proceso de formación y educación a través de las instrucciones y enseñanzas recibidas y como resultado de ese proceso (Romano, 1993: 30).

Es interesante observar, en las palabras de Romano, que la información establece una correlación continua entre lo que el autor denominó de sentido literal "dar forma a la materia" como descripción, concretización, dibujo de imagen, y, al mismo tiempo, en sentido figurado, como formación y educación, al capacitar alguien a algo. Así,

2 Este artículo hace parte de la investigación postdoctoral desarrollada en la Facultad de Ciencias de la Información de la Universidad Complutense de Madrid, bajo la supervisión del profesor doctor Manuel Fernández Sande. En esta investigación proponemos el estudio comparativo de las representaciones mediáticas de sujetos excluidos, los desahuciados en España y los favelados en Brasil, teniendo como soporte mediático, los periódicos con circulación nacional, prioritariamente Folha de S. Paulo y El País. Para este artículo establecemos un recorte específico, privilegiando las características de los soportes de los dos periódicos en la constitución de la información. 
vemos que la información tiene una constitución que le es propia, pero se constituye en la correlación con alguien, y de ahí sale su sentido educativo, de proceso de formación del sujeto. Esta concepción se acerca del entendimiento de Paulo Freire, presentado por Meditsch " [...] cuando cualquier tipo de información es comunicada de una persona a otra con éxito, esto implica que ella no fue a penas transferida, como sería de un disquete a otro en un ordenador, pero fue reconocida por la persona que la recibió" (Meditsch, 1997: 5). Al ponderarnos sobre este segundo aspecto, considerando la información como capacitación, podemos concordar con Meditsch, al proponer que la información periodística constituye conocimiento, al considerarnos que toda apropiación es un proceso de elaboración intelectual individual. Debemos indagar sobre estas cuestiones y preguntarnos sobre las características de la información periodística hoy, y sobre las condiciones de producción del conocimiento periodístico; pues que, una vez más concordando con el autor, las características y entendimientos sobre el conocimiento están históricamente construidos. Para reflexionar acerca de esta cuestión, llevaremos a cabo un análisis comparativo de dos periódicos que constituyen el corpus de esta investigación, observando las características de los soportes que constituyen la información periodística.

\section{Hipótesis}

A partir del entendimiento del periódico como espacio comunicante, proponemos analizar el impacto de las características de espacialidad ${ }^{3}$ del periódico en la constitución de la información periodística. Así, al analizarnos la composición proporción/construcción del espacio, considerando la diagramación y paginación del periódico; la correlación entre infografías, noticias y publicidad, además del uso de colores e imágenes, buscamos demostrar que las formas de los dos soportes comparados son diametralmente distintos, aspectos estos fundamentales para las diferencias establecidas en las características de la información y en las prácticas de lectura. Esto porque entendemos que "estudiar el espacio como territorialidad significa aprehender el modo como, a través de las espacialidades, se puede leer e interpretar la cultura que se sitúa entre espacio y comunicación, directamente condicionada por ellos" (Ferrara, 2008: 59).

\section{Metodología}

Según hemos comentado, este artículo se trata de los resultados de una investigación comparativa. En los dos países, elegimos periódicos con características editoriales parecidas, pautándonos para elegirlos, principalmente por los criterios de circulación nacional y número de ediciones vendidas diariamente. Así es que seleccionamos en

3 Espacialidad es un concepto utilizado por Lucrécia Ferrara comprendido como la articulación de tres componentes: proporción, construcción o reproducción, señalando la correlación de elementos distintos del espacio de un objeto. En el caso del espacio del periódico, la espacialidad se refiere a la composición de los siguientes aspectos: 1. Proporción-diagramación y paginación; 2. Construcción-utilización de infografías, colores e imágenes; 3. Reproducción-correlación entre noticia y publicidad, pues que es mucho más complejo que la referencia a diagramación o características del soporte. 
Brasil el periódico Folha de S. Paulo y en España, El País. Los periódicos fueron observados en tres momentos definidos, momentos estos relacionados a la definición del objeto analizado en el postdoctorado, entre junio y diciembre de 2009; en mayo de 2011 y en el período de noviembre de 2012 a abril de $2013^{4}$.

Proponemos el análisis de las características de los soportes de los periódicos para demostrar que los mismos resultan condicionados por las distintas formas de constitución de la información y del conocimiento, para esto procedemos al estudio de los componentes de espacialidad del periódico que nos permite ponderar sobre sus efectos para las condiciones de visibilidad y comunicabilidad. Partimos de la observación de espacialidad de los mismos, considerando, primero, la organización de la totalidad de periódicos - su paginación, en el modo de constituir sus suplementos y secciones y en el modo de conducir las prácticas de lectura. En secuencia pasamos a analizar la diagramación de las páginas de los periódicos, considerando proporción y construcción de noticia, comparación entre los espacios de las noticias y de la publicidad, además del uso de colores e infografías. Pautados por los componentes de la espacialidad, caminamos en la discusión sobre los efectos de visibilidad y comunicabilidad, considerando los procesos de instrumentalización técnica de la información periodística. Seguimos así, estos pasos propuestos.

\section{Territorios culturales: entre los colecionamentos y los descolecionamentos ${ }^{5}$}

Empezamos con la experiencia del manejo del periódico, su paginación. El periódico El País presenta una organización interna que aquí vamos a denominar de lineal. ¿Qué significa? La construcción de sus temáticas son presentadas de modo continuo, sin ruptura de secciones o de páginas; hay una continuidad que solo es alterada por dos indicaciones presentes en el periódico: en la parte superior derecha hay la palabra 'Menú'y, a la izquierda, la indicación de la sección.

En la práctica, El País no se organiza por secciones independientes, como el periódico Folha de S. Paulo. De esta manera, la lectura del periódico español camina como si fuera una grande vía única, sin paradas, apenas con un pequeño subtítulo separando las temáticas propuestas; al paso que el periódico brasileño es desmembrado en secciones -al modo de cuadernillos diferenciados- y el lector puede elegir la sección que pretende leer de forma independiente. El periódico español, entonces, trae-

4 Estos períodos se relacionan con la condición de los excluidos en los dos países analizados.

5 'Colecionamentos y Descolecionamentos ' son conceptos utilizados por Néstor García Canclini. Para el autor, los "colecionamentos” son sistemas simbólicos estructurados que orientan las prácticas culturales de una sociedad. Están pautados por la fuerte correlación tiempo-espacio, es decir, por las características culturales propias y específicas del lugar, construyendo sentidos y lógicas del poder colectivos. Como una colección organizada en un museo, que trae un trayecto de observación obligatorio, las significaciones culturales son elaboradas de modo hegemónico, según las lógicas del Estado; El concepto "descolecionamento" se refiere a las lógicas que disgregan los sistemas de valores organizados, desmontando la articulación tiempo-espacio, esta situación propia del contexto de la globalización y creando situaciones específicas, personalizadas y fluidas de composición de otras referencias culturales. 
ría una conducción de lectura propuesta como la experiencia de recorrer un museo, un acervo o cualquier otra institución coleccionadora. Ya en el manejo del periódico brasileño, el lector actúa como un descolecionador, apropiándose de las secciones de acuerdo con sus intereses y componiendo así su propia lógica de lectura, pues que "[...] cada usuario puede hacer su propia colección. Las tecnologías de reproducción permiten a cada uno montar en su casa un repertorio [...]" (Canclini, 2006: 304).

También percibimos la gran preocupación visual que el periódico brasileño presenta, al disponer sus secciones a través de recursos visuales resaltados, con el uso de colores e infografías, aspecto este también muy distinto del periódico español. Para ponderarnos sobre esto, vamos a nos basar en Lucrécia Ferrara, tratando ahora, paginación y diagramación a través de conceptos propios de análisis del espacio. Según ella, la forma de organización del espacio, para nosotros el espacio del periódico, puede ser percibida por el análisis del modo como se constituyen la espacialidad y, en consecuencia, la visibilidad propuesta. La espacialidad propone una organización del uso del espacio que constituye un modo de visibilidad. Así, la espacialidad de El País se estructura en la centralidad del texto, a pesar de haber las fotografías componiendo el reportaje; como hemos visto, la diagramación de la página está organizada a partir de la predominancia de la palabra escrita, en textos extensos y continuos. El texto es, por sí solo, lineal en su constitución, garantizando una lectura dirigida, por supuesto, creando una visibilidad de totalidad y continuidad, muy perceptibles en la figura 1:

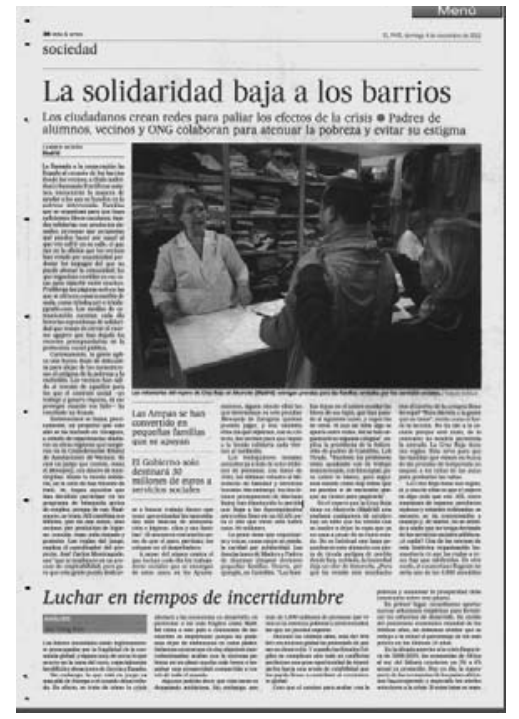

Figura 1. El País, 04/11/2012, p.36

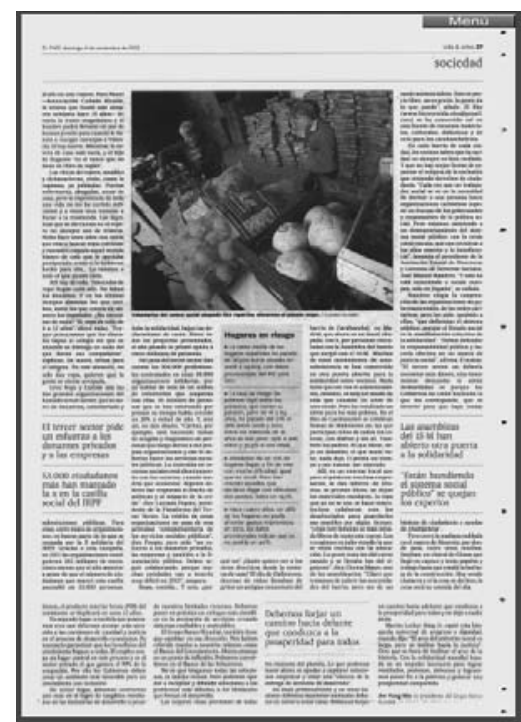

Figura 1. El País, 04/11/2012, p.37

Se trata de páginas de El País, del día 4 de noviembre de 2012, páginas 36-37. Podemos notar que hay un único reportaje desarrollado en la totalidad de las dos páginas, presentadas a partir de un único subtítulo. El reportaje aborda la crisis económica española, a partir de los lazos de solidaridad sociales organizados desde la acción de ONGS y sectores comunitarios en un diálogo con sectores económicos privados y en 
la presión para una acción del Estado. La observación de ediciones relativas al recorte temporal propuesto para esta investigación nos demuestra un estándar referente al trato del reportaje periodístico, pensada aquí en sus formas de paginación/diagramación, considerando: tamaño, posición en la hoja, rupturas del texto, presencia de recursos visuales, entre ellos las publicidades; distintas, una vez más, al modus operandi brasileño. En el caso español, los reportajes son más extensos, presentando una tipología de diagramación de páginas compuesta por pocos reportajes, pero más largos. Podríamos considerar un estándar, presentar reportajes políticos, económicos y sociales, todavía más sobre el tema de las crisis, de modo más extenso, pero observamos que este es un modus operandi en la totalidad del periódico.

Como apunta Chartier "[...] es fundamental recordar que ningún texto existe fuera del soporte que le confiere legibilidad; cualquier compresión de un texto, no importa qué tipo, depende de las formas con las cuales llega al lector" (Chartier, 2001: 220), o sea, Chartier considera imprescindible evaluar las características de formatos industriales, como nos diría Martín-Barbero, para comprender las significaciones constituidas. En este sentido, la forma también es contenido y las significaciones se construyen en la articulación de la forma con las especificidades de los rituales de lecturas y de las matrices culturales de sus lectores en el contacto con la lectura específica. Pero, además, el autor indica:

Así, es necesario hacer una distinción entre dos tipos de aparato: aquellos impuestos por la colocación en forma de texto, por las estrategias de la escritura e intenciones del 'autor', y aquellos que resultan de manufactura del libro o publicación, producidos por la decisión editorial o a través de procesos industriales, y dirigidos a los lectores o a lecturas que pueden no tener absolutamente nada en común con las expectativas del autor. (Chartier, 2001: 220).

Es sobre esta caracterización del soporte que aquí discutimos, pues estamos ponderando sobre un contenido - reportaje periodístico - estructurado dentro de una diagramación en la que ella misma constituye significados. Las distinciones en la diagramación de los dos periódicos para nosotros son fundamentales en la comprensión de los significados del contenido periodístico y de la visión del mundo constituida en cada país. Apuntamos hasta aquí la estructuración de las secciones del periódico y el proyecto gráfico y diagramación de las páginas de los periódicos, considerando la forma del reportaje periodístico. Señalamos abajo (fig.2) un ejemplo de diagramación de la Folha de S. Paulo, en los aspectos aquí abordados, referente a la sección "Cotidiano", para establecer una visión comparativa con El Pais, del que anteriormente hemos resaltado un reportaje de la sección "Sociedad".

Vemos la diferencia de la noción de totalidad observada en El País, una espacialidad fragmentada en distintos reportajes y entremezclada de anuncios publicitarios. Ambas son entrelazadas por fuertes recursos visuales, como el uso de colores, uso inusitado del espacio, infografias, motivando una observación rota. Si en el caso español la espacialidad lineal proporciona una visualidad con sentido de totalidad, incentivando a la lectura del texto, en este caso la espacialidad fragmentada viabiliza una visibilidad que fomenta el sensorio, incita y al mismo tiempo entrena un mirar fragmentado, que se dispersa. Aquí vislumbramos una espacialidad y visibilidad en 
mosaico. Esta afirmación está basada en Marshall McLuhan, al proponer la noción de mosaico, comprendiendo que "el periódico recorta acontecimientos de la comunidad y los disponen "como masa de tópicos discontinuos y sin conexiones... que acoge la inclusión de muchas tribus y la diversidad de las visiones particulares" (McLuhan in: Zilocchi, 2007: 77). En esta perspectiva, la estructura en mosaico responde a las características propias de este contexto de liquidez: fluidez, fragmentación o flexibilidad; y, al mismo tiempo, constituyéndose como noticia, busca signos de impacto, que pueden ser verbales o visuales, transformando tanto la publicidad cuanto la información periodística en productos impactantes. Podemos observar en la figura 2 estas características presentes en la organización de las páginas internas de la sección "Cotidiano": los reportajes son cortos y entrecortadas por publicidad, en diagramaciones variadas y visualmente fuertes:

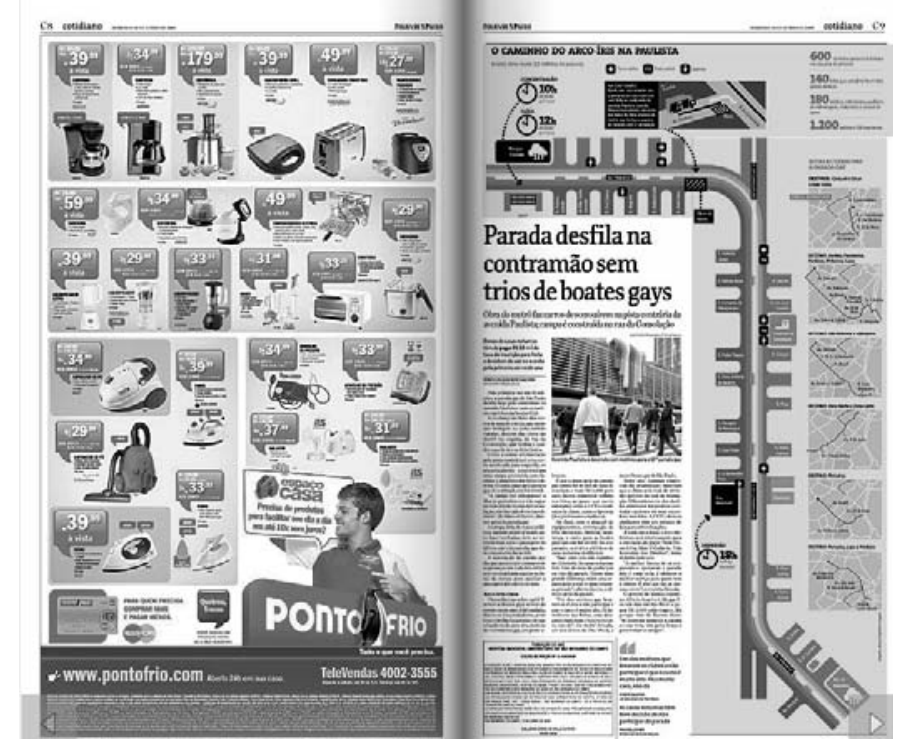

Figura 2. Folha de S. Paulo, 14/06/2009

Por tanto, leer esa imagen en mosaico significa leer jerarquías de tamaños y proporciones, centralizaciones, diálogos y conflictos entre textos e imágenes. Significa leer también manifestaciones de tiempo y espacio que revelan aspectos de la cultura local y global (Zilocchi, 2007: 78).

Retomando el concepto de descolecionamento propuesto por Canclini y utilizado en esta investigación, entendemos que el mismo viene acompañado de la idea de desterritorialización, "con eso me refiero a dos procesos: a la pérdida de la relación natural de cultura con los territorios geográficos y sociales y, al mismo tiempo, ciertas recolocaciones territoriales relativas, parciales, de las viejas y nuevas producciones simbólicas" (Canclini, 2006: 309). Al se romper con las lógicas tradicionales de organizaciones socio-culturales, en este contexto de globalización e intensa dependencia tecnológica, viabilizamos el contacto con otras influencias culturales, aparentemente en una lógica 
más autónoma de recolecionamentos. En el ámbito del periódico, leemos la dupla descolecionamento/desterritorialización en la articulación reportaje/publicidad. Mientras las noticias periodísticas obligatoriamente establecen una continua relación con las tradiciones locales, la publicidad es claramente desterritorializada, muchas veces proponiendo productos/lógicas simbólicos extraños o distintos a las prácticas locales, en un continuo diálogo global-local en su composición. Caminando en esta reflexión, comprendemos mejor la organización del periódico Folha de S. Paulo que se constituye de modo descolecionado, se abre a las posibilidades de desterritorialización a partir de la presencia masiva de la publicidad. Distintamente de El País, que en la composición de su suporte, leído por nosotros como 'tradicional'y organizado con lógicas de totalidad, no está pautado por el peso masivo de la publicidad, que según nuestra argumentación, la desterritorialización de la prensa es visible por la presencia intensiva de anuncios publicitarios. Parece claro que descolecionamento/desterritorialización y lectura en mosaico se complementan mutuamente.

En un análisis más profundo de la publicidad de los dos periódicos, observamos $E l$ País del 1 de noviembre de 2012, para verificar la proporción de la publicidad presente en toda su edición. Considerando la totalidad de 83 páginas, recorremos la observación por temática y llegamos a los siguientes números: la sección "Internacional", compuesta por 11 páginas, presentó 2 páginas con publicidad integral, o sea, ocupando toda la página, y 2 anuncios publicitarios con media página; en "Nacional", compuesto de 10 páginas, hay 2 páginas con publicidad integral y un anuncio de media página; las secciones de "Economía", "Opinión" y partes del "Vida e Arte" no presentaron ningún anuncio; "Sociedad" tuve una totalidad de 6 páginas conteniendo 2 de ellas con publicidad integral. En proporción, la realidad brasileña es muy distinta. Observemos el ejemplo abajo (fig.3), adoptando el argumento de que la publicidad es desterritorializada, por proponer el consumo aleatorio (vinculado o no al local) y buscando ahora, analizar la proporción de espacialidad al considerarla en la diagramación del periódico:

La portada de este ejemplar de la sección "Cotidiano" contiene apenas un titular de un reportaje que será desarrollado en el interior del mismo "empeora la cualidad del agua subterránea en Sao Paulo", acompañada de una fotografía en el lado superior derecho de la página. Podemos observar rápidamente la desproporción de la distribución del espacio entre la información periodística y la publicidad. Esta composición en la sección analizada es continua, demarca una estrategia que es económica, política y cultural. Considerando las características de esta espacialidad, ya constituida como reproducción, destacamos la descripción de su proporción y construcción. Inicialmente, percibimos cuatro formas de

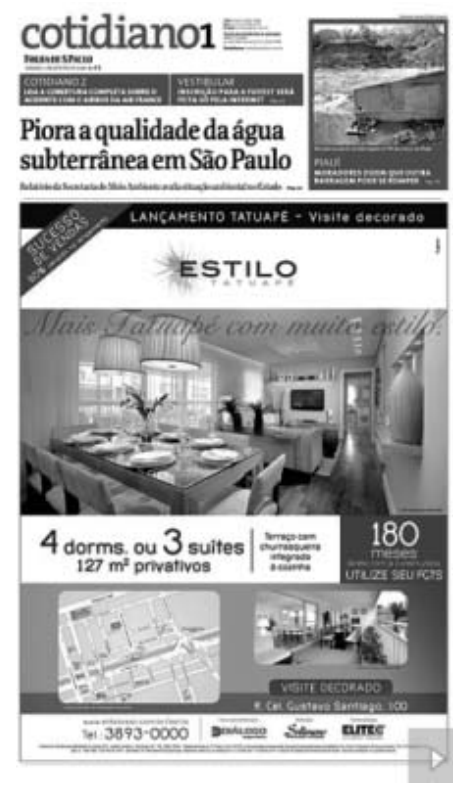

Figura 3. Cotidiano, 06-06-2009 
distribución del espacio de la página del periódico $0^{6}$, observando la portada de la sección "Cotidiano". Fijémonos, ahora, para su constancia, recortando apenas la sección "Cotidiano". En la primera columna están los meses inicialmente analizados en este proyecto; y en las otras columnas están la cantidad de publicidad por mes en los diferentes formatos. Miremos la tabulación:

\begin{tabular}{|l|r|r|r|r|r|}
\hline \multicolumn{1}{|c|}{2009} & PP & MP & PI & Casi PI & SP \\
\hline Junho & 4 & 11 & 13 & & 2 \\
\hline Julho & 1 & 9 & 15 & $\overline{3}$ & 3 \\
\hline Agosto & 7 & 6 & 15 & 2 & 1 \\
\hline Setembro & 4 & 8 & 16 & 1 & 1 \\
\hline Outubro & 4 & 5 & 22 & - & - \\
\hline Novembro & 5 & 9 & 17 & 2 & - \\
\hline
\end{tabular}

Podemos observar que hay una regularidad entre la proporción de publicidad PP y MP y la totalidad de publicidad PI, y, exceptuándose el mes de junio, las portadas con PI prevalecen y ocupan más de la mitad del mes, lo que entendemos, por tanto, que se caracteriza como un estándar de utilización de las portadas de la sección "Cotidiano". Si la comercialización de la publicidad en la prensa es medida por el tamaño del espacio utilizado, constatamos la prevalencia de la misma en relación a la información periodística en las portadas de esta sección, y entendemos que el periódico necesita de la publicidad para su propio mantenimiento; sin embargo, entendemos que esta formación indica un cambio en el significado de su producto principal, la información periodística.

La primera observación ya indica una desproporción en la distribución de este espacio, al considerar la proporcionalidad en el tiempo pues, como mínimo, durante la mitad del mes la portada privilegia la publicidad frente a la información. Además, debemos considerar la proporcionalidad del espacio valorado de página, pues "[...] la página impar es más cara que la página par y el centro de página es más caro que el rodapié, entre otras jerarquías" (Zilocchi, 2007: 78). Esta ocupación no se detiene apenas a la portada, siendo continua su presencia en el cuerpo de la sección en diferentes proporciones.

Nos parece que la información periodística, inicialmente el producto central del periodismo, concurre en desventaja con la publicidad, observándose la distribución y construcción en el espacio, garantizando visibilidad extensiva a la publicidad; es decir, en la composición espacialidad-visibilidad hay la prevalencia de la publicidad sobre la información periodística. Al ponderar sobre este aspecto, debemos considerar estudios que redimensionan las características de la información periodística en su relación con el entretenimiento, cambiando los sentidos constituidos tanto para la

${ }^{6}$ Como podemos observar la sigla PP hace referencia al pequeño anuncio publicitario, ocupando mitad de $1 / 3$ de página; $\mathrm{MP}$-anuncio que ocupa $1 / 2$ página; $\mathrm{PI}$ - anuncio que ocupa página entera, teniendo o una columna de texto o apenas el titular del reportaje que será discutida dentro de la sección. Proponemos, la denominación 'casi PI', pues utiliza dos columnas de texto, con la publicidad en la vertical, como presentado. Tenemos, también, el SP - sem peça (anuncio) publicitario, que prevalece en situaciones en que el reportaje presentaba alguna tragedia. 
información cuanto para la publicidad. En este momento, considerando la publicidad, vemos la posibilidad del entendimiento de que la misma también sea vista como noticia e información. "Y la inversión en que el espacio del anuncio se sobrepone al espacio de la noticia, que nosotros tratamos en este texto, nos permite afirmar que el anuncio publicitario es noticia y también información" (Zilocchi, p. 84).

Llevemos en cuenta algunas gradaciones reflexivas para esta información. Primero el hecho de que el anuncio publicitario contiene información, ciertamente relacionada al producto anunciado; esto, sin embargo, no implica que la misma tenga carácter noticioso. Según Gomes (2003: 1): "En una visión socio discursiva, el acontecimiento es construido simbólicamente dependiendo del lugar valorativo de aquel que le produce. El acontecimiento se torna evento noticioso cuando modifica alguna cosa en el orden establecido, o cuando se percibe que algo en el acontecimiento podrá provocar un efecto de saber, de prominencia o destaque". A partir de esta premisa, difícilmente podríamos considerar el anuncio publicitario efectivamente una noticia, a pesar de identificar cada vez más un sentido noticioso en la misma por la busca de novedad, tanto por las características del producto cuanto por la presentación del producto y del anuncio publicitario en la diagramación de la página.

Considerando, todavía, que el todo de la espacialidad del periódico se constituye en procesos de representación, o sea, en la experiencia constituida a partir del espacio del periódico, tomándose la composición de sus tres categorías, ocurre no por la vivencia, sino, por la apropiación de representaciones constituidas, creando una lógica propia de comunicabilidad, un modo de leer el mundo; entendemos así que posibilita la construcción de un conocimiento históricamente específico y dado. Para esta reflexión, partimos de la premisa propuesta por Ferrara de que la espacialidad es parte constituyente de la "comunicación ideológica de la cultura", es decir, la espacialidad es componente comunicante y la comunicación es discurso y reflejo de las características de una cultura.

En la parte destacada notamos la importancia de la publicidad en la articulación de aspectos, experiencias y perspectivas globales en contrapunto o composición con el reportaje de la sección "Cotidiano", de características esencialmente locales. Observemos la figura abajo (fig. 4).

La portada de esta edición articula un reportaje "Después de la confrontación, Heliópolis pide mejor tratamiento", cuyo titular resalta un deseo de condición social y un anuncio publicitario que expone este deseo de forma clara, en un proyecto de vivienda. La articulación reportaje y anuncio publicitario ya había aparecido en la figura 8, con la misma correlación. Tenemos una espacialidad fragmentada, en mosaico, y su visualidad demarcada por la preponderancia del anuncio publicitario y la articulación entre el titular

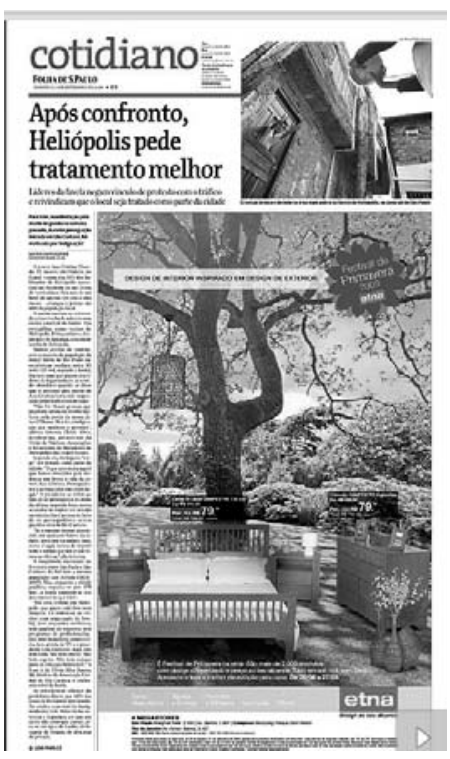

Figura 4. 06/09/2009 
del reportaje y la imagen de la propaganda garantizando la visualidad de proyectos sociales. En este caso, el "mejor tratamiento", presente en el titular del periódico está asociado a dos imágenes que se refieren al que se entiende por calidad de vida; son dos imágenes de residencias, contrapuestas y, de cierta manera, son dos productos distintos dentro de la diagramación de la portada. Pero el diálogo que se articula demuestra, primero, la estrategia del mercado que rige las perspectivas sociales, señalando que, dentro de la lógica capitalista, un lugar circunscrito, la felicidad se logra con dinero y capacidad de consumir estos productos materiales y simbólicos incluyendo en la visión de los sujetos sociales los objetos de deseo y definiendo 'un dominio de los lugares por la visión'. Simultáneamente, como hemos indicado, las noticias presentan un tema relevante para la contemporaneidad, la idea de bienestar, constituyendo sentido simbólico, como información. Así, la comunidad pide un mejor tratamiento y el mercado ofrece la intimidad de la casa, en la relación con la naturaleza. En este momento nos preguntamos, una vez más, entonces, sobre el sentido de la información periodística. Hemos tratado, hasta ahora, de la aproximación de la publicidad y del reportaje a la noticia, estructurando la preocupación con el impacto y el movimiento. En este proceso, se convierten en productos culturales y de consumo. Ambas constituyen información y exploran aspectos noticiosos relativos al bienestar, aspecto central de la cultura en cuestión. Además, considerando la visualidad, la publicidad incita la mirada más que la noticia. En este caso, publicidad e información periodística se integran, no se disocian y dejan en duda quien informa más: el reportaje o la publicidad.

En esta perspectiva simbólica y observando la cultura en el ámbito de la institucionalidad, que nos lleva a considerar la totalidad del periódico como un producto, al observar su formato industrial (Martin-Barbero) y el sentido de tecnicidad en esta lógica de producción, constatamos que el valor-noticia constituido en las páginas del periódico, pone en disputa continua la información periodística y el anuncio publicitario, favoreciendo el segundo. Así, en la observación de las prevalencias en cuanto condiciones de espacialidad y visibilidad, volvemos a la discusión anterior redimensionando tanto el sentido de la información cuanto de la publicidad y observando ambos, componentes de información y noticia, entendemos que los periódicos analizados tienen tratamientos distintos para la cuestión. En el caso de la Folha de S. Paulo, defendemos la idea de que la publicidad se convierte en noticia.

Por fin, hay que se considerar la relación establecida hoy entre el periódico (formato industrial) y el público - lector en su capacidad de recepción, que nos lleva a destacar las ritualidades de recepción:

En su relación con los FI (discursos, géneros, programas y grades o palimpsestos), las ritualidades constituyen gramáticas de acción - del mirar, del escuchar, del leer - que regulan la interacción entre los espacios y tiempos de la vida cotidiana y los espacios y tiempos que conforman los medios. Que implica, de parte de los medios, una cierta capacidad de imponer reglas a los juegos de significación y situación (Martín-Barbero, 2003: 19).

Ya hemos apuntado para las diferencias en la gramática del mirar, en el ejercicio de manipulación del periódico, en la ruta del mirar. En este recorrido, demostramos distinciones entre los dos periódicos, en el modo de lectura de las secciones y suple- 
mentos y en las especificidades de la constitución de las diagramaciones de página. Continuaremos en este último aspecto más allá de la reflexión específica sobre la publicidad. Como hemos señalado, el periódico brasileño trae una estructura textual y visual fragmentada, mientras que el periódico español favorece una lectura más lineal y un sentido de totalidad.

\section{Comunicabilidad e instrumentalización técnica}

Proponemos, ahora, reflexionar sobre las condiciones de comunicabilidad, comprendiendo que debemos articular las características del que es comunicado en el diálogo con el proceso de comunicación. Hemos visto, hasta ahora, una nueva estructuración del contenido periodístico, redimensionando lo que es la noticia, incorporando la publicidad en su propósito y proponiendo un proceso de lectura en mosaico. La condición del soporte cambió y su función mediadora también. Dialogando con Muniz Sodré, entendemos que en realidad se configuran procesos de mediatización más que los procesos de mediación:

Qué sustenta es la tendencia a la substitución del discurso objetivista, argumentativo y racionalista, compatible con la prensa clásica, por la narrativa (en forma de caos) emocional de mediatización, que significa cambiar la opinión razonada por la percepción esteticista del performance (Sodré, 2011: 41).

Pensemos sobre la mediatización por partes. Como es discutido por el autor, la mediatización presupone, en su estructura visible, la tecno interacción, que compuerta la incorporación de tecnologías en el acceso a la información, aspecto este reforzado y ampliado por Martín Barbero (2003: 150-152): “[...] propongo las 'mediaciones comunicativas de cultura' que son: 'tecnicidad'; 'institucionalidad' creciente de los medios como instituciones sociales y no como aparatos, instituciones de peso económico, político, cultural; la sociabilidad [...]”. Esto es visible en la proliferación de medios de comunicación pos masivos, así como, en los cambios procesados en la propia prensa, que comenzó a ofrecer, paralelamente, su contenido en formato digital. Esto es visible también en la instrumentalización técnica de la información, o sea, en la manera como es procesada y leída, aspecto este ya discutido y resaltado por Sodré al señalar, como transformación principal, la evolución de la lectura lineal para la lectura en mosaico, caracterizando lo que el autor denominó de 'discurso objetivista, argumentativo y racionalista... para la narrativa (en forma de caos) emocional...'. Este pasaje indica cambios en las estrategias utilizadas en la confección de la edición, así como en el procedimiento de lectura. Debemos recordar que la estructura en mosaico, que destaca la noción de noticia e incorpora la publicidad, responde, claramente, a la lógica de mercado.

Aquí empieza, según el autor, lo que la mediatización no demuestra. Esta se sustenta en la percepción en oposición a las lógicas tradicionales de mediación, basadas en la racionalidad argumentativa. Al priorizar el sensorio hay la necesidad de motivarlo creando, entonces, en el caso de la prensa - objeto de discusión de este artículo -, la preocupación continua con la proporcionalidad de las noticias y el cuidado con su composición significativa. Como también ya se ha abordado, en esta lógica, la lectura 
se da en mosaico, pues la percepción no exige linealidad, sino, motivación y constancia; para Sodré, aquí se constituye lo que él denomina de lógica indiciaria en oposición a la lógica simbólica. En esta, se privilegian los valores sociales y en el índice se garantiza la posibilidad de relación con la realidad, constituida de modo fragmentado y disperso, y de ahí viene la idea de 'índice e caos'. Al pasar de la lógica simbólica para la lógica indiciaria hay la constatación de que la sociedad perdió sus valores simbólicos y, en consecuencia, las instituciones mediadoras de este proceso. Esto conlleva el hecho de que estas instituciones (familia, escuela, iglesia, instituciones políticas, entre otras) perdieron la capacidad de elaboración de significación del mundo, lo que significa, en otras palabras, que perdieron su fundamentación ética, su gama de valores estructurantes.

$11 / 06$

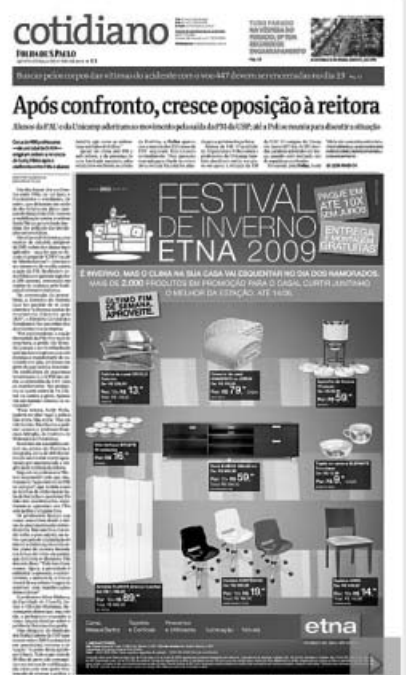

$13 / 06$

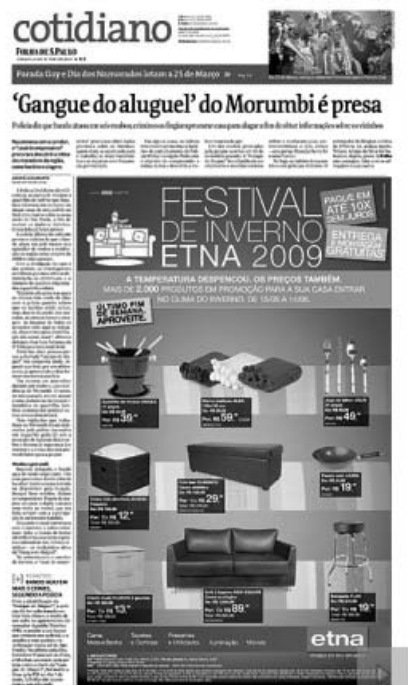

$14 / 06$

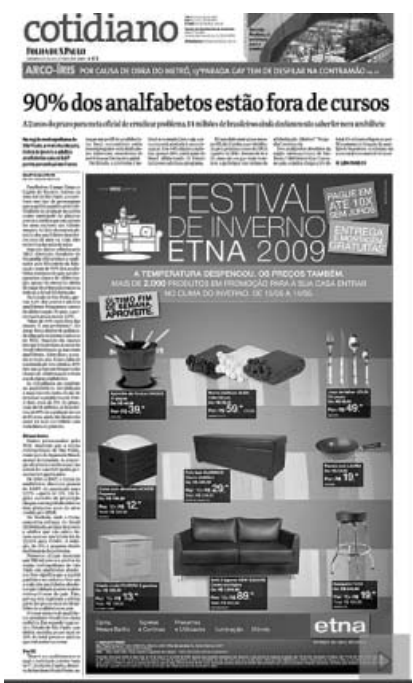

Figura 5. Portada de la sección Cotidiano en las fechas arriba indicadas

Así, los sentidos deben ser continuamente movilizados para crear sensaciones, y, la movilización se hace por el aguzamiento continuo de estos mismos sentidos, explorándose colores, proporciones, diagramaciones inusitadas y excesos. Al considerar específicamente el texto verbal, notamos las estrategias construidas tanto en la correlación de los titulares con las imágenes y los textos, cuanto en la exploración de la narrativa emocional. Si el sensorio necesita de movilización continua, el sentido visual, en este proceso de movilización, procede en la decodificación de las informaciones buscando, primero, aspectos reconocibles. Esto es interesante, pues identificamos en la Folha de S. Paulo, que se constituye por esta lógica, un tipo de estrategia publicitaria que en lugar de buscar sorprender al público para captar su atención y garantizar el impacto, opta por la repetición de una misma narrativa con el objetivo de que resulte tan conocida por el lector que éste reciba los mensajes publicitarios integrados a los contenidos puramente informativos. Observemos la figura 5. Ella pre- 
senta tres portadas de la sección "Cotidiano" de ediciones prácticamente consecutivas. Y, en nuestro punto de vista, componen, junto con la diagramación del espacio del periódico, parte de las estrategias del mismo. Entendemos aquí por estrategias, no solo la articulación con los intereses de mercado, aspecto este obvio, pero también la instrumentalización técnica de espacios que serían, originalmente, de construcción racional del conocimiento. Como indica Miranda, "esto se debe especialmente a la incapacidad para percibir el nuevo papel de la técnica que dejó de ser un simple instrumento racional, un medio, para afectar crecientemente la propia constitución de experiencia contemporánea" (Miranda, 2002: 8).

A esto, este mismo autor llama de esteticização ${ }^{7}$ de la experiencia, recordándose que Walter Benjamin fue el primero a percibir la instrumentalización técnica del mundo, ocurrida primeramente en el ámbito del arte y, hoy, muchos autores (Miranda, Sodré y otros) discuten la instrumentalización de la experiencia, ocupando todos los ámbitos de la condición sensible.

En los medios audiovisuales este proceso es fácilmente perceptible, pues explora los diferentes sentidos, como también en los textos de prevalencia del no verbal, por el predominio de la imagen. Nos disponemos, sin embargo, a ponderar sobre este proceso en la prensa, compuesta prioritariamente del texto verbal; comprendemos que la prensa también procede de la misma forma, a través de los soportes que le son propios, pues al final, lo que constatamos es que el sensorio también es ejercitado para un tipo de procedimiento y esto porque, como nos muestra Miranda, la palabra también está dominada por la técnica:

Esto pasa por el ocultamiento e inmaterialidad de la técnica, pero también por su completa inmersión en la historia y en los cuerpos, como demuestran las biotecnologías, las implantaciones, las prótesis, la ingeniaría genética. La frontera entre bios y la techné está puesta en causa, con que se llega a una situación límite. La palabra que caracterizaba el humano como animal racional (Aristóteles) no puede dejar de salir sin lesión de esta fusión del biológico y del tecnológico (Miranda, 2002: 110).

Buscamos identificar en este artículo algunas lógicas que explicitan el predominio de la técnica, teniendo claro que no abordamos todos los aspectos que nos llevarían a las variadas articulaciones textuales y temáticas. En el caso de la figura 12, vimos el procedimiento de acomodación del mirar, pues inmediatamente reconocemos la imagen y su significación. Eso, por un lado, refuerza el mensaje, resaltando la función económica de la publicidad y, por otro lado, ejercita la distracción, como procedimiento sensorio, pues es conocido y repetido. Benjamin (1985) ya había propuesto esta discusión al elaborar el concepto de 'recepción táctil', demostrando como los nuevos artes, cine y fotografía, ejercitaban la distracción perceptiva, conducida por los medios. Vemos, abajo, esta lógica reforzada, explorando, ahora, el estímulo del texto verbal:

${ }^{7}$ En este caso, la palabra 'esteticização' fue tomada de Bragança Miranda, cuya grafía es del portugués de Portugal. En el restante del texto, aparecerá como 'estetização', en versión brasileña, como utilizada por Muniz Sodré. 
Día 25/08

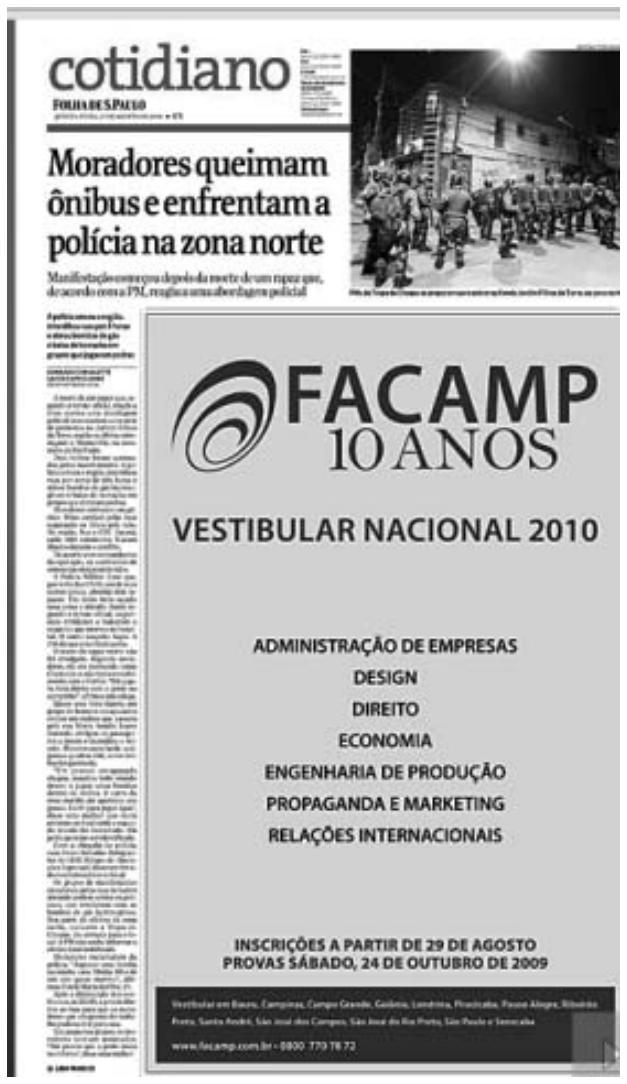

Día 02/09

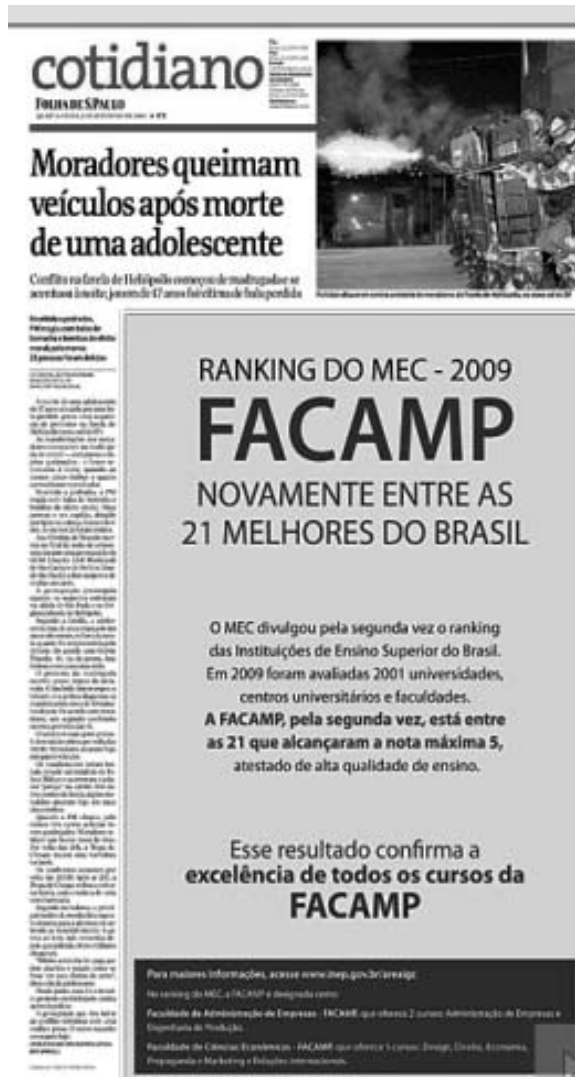

Figura 6. Portadas de la sección Cotidiano con las fechas señaladas arriba

En este segundo caso, no solo el producto de los anuncios publicitarios es el mismo, como el propio texto se repite, pues comienzan de la misma forma: 'Moradores queman...' ¿Qué es que esta técnica provoca en la lectura cotidiana del periódico? O, preguntando de otra manera, ¿qué recepción táctil provoca en el proceso de comunicabilidad? O aún, retomando a Sodré, ¿qué efectivamente no está visible en el proceso de comunicación mediatizado?

Basándonos en Baitello (2005), podemos identificar un continuo proceso de incomunicación, generado por el exceso de signos, por la dispersión de la composición, por la repetición del verbal, confundiendo o dispersando el lector, aspecto este central de la incomunicación. Al mismo tiempo, las imágenes presentes en la diagramación de la página son imágenes vacías, así como, las imágenes creadas por la lectura del periódico son limitadas y ambas son incapaces de alimentar el imaginario y, en consecuencia, provocar la imaginación. Para Baitello, entonces, si la información no genera comunicación, no es capaz de vincular y no se vincula, solo conecta, no hace efectiva la propia comunicación. 
Hemos visto a Muniz Sodré caminando en la misma reflexión, al entender que se conforma un $4^{\circ} \mathrm{Bio},{ }^{8}$ pautado por el ethos mediático y es, justamente en este aspecto, que podemos comprender lo que el autor denominó de estrategias no visibles para la manutención de una lógica hegemónica.

El ethos expresa un modo de ser, señalando formas de sociabilidad. Para Muniz, se configura el 'ethos mediatizado' "cada vez más construido por las dimensiones variadas del entretenimiento o de la estética, en sentido amplio, cuyos recursos provienen del imaginario social, del ethos sensorial y del subjetivismo privado" (Sodré, p. 40). Este ethos, pautado por la 'estesia"' mediática obedece a la misma lógica del consumo, vaciando un carácter ético, ahora centrado en el hedonismo, que es individual. Se pierden referencias y valores colectivos y, en su lugar, se valoriza al individuo en sus deseos y lecturas individuales. Hemos visto que el periódico, entonces, constituye la información como noticia, incorporando reportaje y publicidad, siendo que esta segunda refuerza continuamente el hedonismo. Vimos, aún, que los sentidos son aguzados, en un ejercicio de lectura fragmentada, dispersa, caótica.

La reflexión propuesta en este artículo no encierra el debate teórico-conceptual que suscita en su principio, dada la complejidad del tema y posibilidades de abordajes. Nuestro intento fue de ponderar sobre el texto periodístico en el contexto contemporáneo, a partir de perspectivas demarcadas por nuestra proposición, analizando específicamente las condiciones del soporte. Así, entendemos que vivimos una nueva lógica cultural, considerando que las características de la cultura contemporánea sufrirán profundas transformaciones en sus paradigmas. Buscamos observar el papel del periódico hoy, en este nuevo contexto cultural, ponderando sobre su capacidad de comunicación, vinculación y de construcción del conocimiento, en la comparación de dos productos distintos inseridos en culturas distintas. Percibimos que la configuración de la información periodística camina hacia los mismos resultados, presentando, sin embargo, resultados distintos en la comparación de los dos periódicos debido, en nuestra visión, justamente a las características culturales de cada contexto. En este sentido, resaltando el caso brasileño, recuperamos el entendimiento genérico que es la información y su articulación con el mercado y percibimos el proceso de construcción de incomunicación, por confundir, exceder, fragmentar, repetir; después, o al mismo tiempo, la 'estetização' de la experiencia, afectando de la misma forma el sentido del conocimiento y de la condición sensible. Segundo Haroche:

8 Para discusión del $4^{\circ}$. Bio, Muniz Sodré retoma Aristóteles. Este filósofo entendía que el Hombre podría relacionarse con el mundo a través de tres modos, el Bios - 'A vida Contemplativa', propia de los filósofos; 'la vida política', propia de los ciudadanos y, por último, 'la vida del cuerpo', traducida por Arendt como la vida del labor, o sea, aquella pautada por la necesidad. Sodré entiende que se conforma ahora, una otra forma de se relacionar con el mundo, o un $4^{\circ}$. Bios, que sería la 'esfera de los negocios', que pasa a articular la experiencia cultural a la lógica del mercado, desvinculada de los valores que la sustenten.

9 Según el Diccionario Aurélio de lengua portuguesa (Brasil), 'estesia’ significa: "Sensibilidad excesiva o dolorosa". 
Las condiciones de apropiación y de transmisión de los saberes en las sociedades contemporáneas están profundamente trastornadas: la creciente masa de informaciones continuas en las sociedades contemporáneas, concomitantemente a una reflexividad y una fluidez permanente, contribuye para las formas inéditas del individualismo, conduce a una fragmentación, una dispersión, una falta de compromiso que obstruye de cierto modo la continuidad, el sentimiento de sí mismo (Bauman, 2000; Sennett, 1998; Kauffmann, 2003) (Haroche, 2005: 350).

En la reflexión al largo de su texto, Haroche profundiza la propia idea de lo que serían los saberes y basándose en Gauchet (2002) propone: "induce a un saber no cumulativo, estrictamente especializado, rápidamente superado y ultrapasado. Se produce en el pensamiento una pérdida de inteligibilidad, una pérdida de sentido, una especialización sin fin ni razón, una inelegibilidad" (Haroche, 2005: 356). En este sentido, retomando el inicio de nuestro texto, podemos aún concordar con Meditsch, al entender que la información periodística produce conocimiento pero, basado en Muniz y Haroche, precisaríamos cuestionarnos las características de este conocimiento.

\section{Referencias bibliográficas}

BAITELLO, Norval (2005): A era da Iconofagia, São Paulo, Ed. Hacker.

BAITELlO, Norval (org.,2005): Os Meios da Incomunicação, São Paulo, Annablume.

BAUDRILLARD, Jean (1991): Simulacros e Simulação. Lisboa, Relógio D’Agua.

BAUDRILLARD, Jean (2000): O Sistema dos Objetos. São Paulo, Perspectiva. BAUMAN, Zygmunt (2007): Vida líquida. Rio de Janeiro, Jorge Zahar.

BAUMAN, Zygmunt (1999): Globalização- as conseqüências humanas., Rio de Janeiro, Jorge Zahar.

BENJAMIN, Walter (1985): Obras Escolhidas I- Magia e Técnica, arte e política. São Paulo, Brasiliense.

CANCLINI, Nestor G. (2006): Culturas Hibridas. São Paulo, Edusp, 4. ed.

CANCLINI, Nestor G. (2002): "Cidades e Cidadãos imaginados pelos meios de Comunicação". Opinião Pública, Campinas, Vol. VIII, no 1, pp.40-53.

CHARTIER, Roger (1991): "O Mundo como Representação". Estudos Avançados, vol. 5, num. 11, abril.

CHARTIER, Roger (1990): A História Cultural- entre práticas e representações, Lisboa, Difel.

CHARTIER, Roger (2001): Textos, impressões e leituras IN Hunt, Lynn. A Nova História Cultural. São Paulo, Martins Fontes.

DEBORD, Guy (1997): A Sociedade do Espetáculo. Rio de Janeiro, Contraponto. 
FERRARA, Lucrécia D’Alessio (org., 2007): Espaços Comunicantes. São Paulo, Annablume.

FERRARA, Lucrécia D’Alessio (2008): Comunicação, Espaço, Cultura. São Paulo, Annablume.

FRANÇA, Vera (2012): “O acontecimento e a Mídia”. Revista Galáxia (online), São Paulo, n. 24.

GINZBURG, Carlo (1989): O queijo e os Vermes, São Paulo, Companhia das Letras.

GINZBURG, Carlo (2009): Mitos, Emblemas e Sinais, São Paulo, Companhia das Letras.

HABERMAS, Jürgen (1984): Mudança Estrutural da Esfera Pública. Rio de Janeiro, Tempo Universitário.

HAROCHE, Claudine (2005): A Condição Sensivel. Rio de Janeiro, Contra Capa.

HAROCHE, Claudine (2008): "Crise da consciência contemporânea e expansão do saber não cumulativo". Revista Educação e Pesquisa, São Paulo, vol. 31.

LAGE, Nilson (2005): Teoria e Técnica do Texto Jornalístico.Rio de Janeiro, Edit. Elsevier.

MARTÍN-BARBERO, Jesús (2003): Dos Meios às Mediações. Rio de Janeiro, Edit. UFRJ.

MEDITISCH, Eduardo (1997): “O Jornalismo é uma forma de Conhecimento?”. (conferência feita nos Cursos da Arrábida - Universidade de Verão) revistas.univerciencia.org.

MIRANDA, José A. B. (2002): Teoria da Cultura. Lisboa, Edições Século XXI.

ORTIZ, Renato (2006): Mundialização: saberes e crenças, São Paulo, Brasiliense.

ROMANO, Vicente (1993): La formación de la mentalidad sumisa. Madrid, Ediciones Endymion.

SANTOS, Milton (2006): Por uma Outra Globalização. Rio de Janeiro, Record.

SODRÉ, Muniz (2011): Antropológica do Espelho, Petrópolis, Vozes.

SODRÉ, Muniz (2006): As Estratégias Sensíveis. Petrópolis, Vozes.

THOMPSON, Edward P.(1998): Costumes em Comum. São Paulo, Companhia das Letras.

TRAQUINA, Nelson (2005): Teorias do Jornalismo. Vol. 1: Porque as noticias são como são. Florianópolis, Insular.

ZILOCCHI, Ana Maria D. (2007): "Espaço: entre a notícia e a informação". In FERRARA, Lucrécia D’Alessio (org): Espaços Comunicantes, São Paulo, Annablume. 


\section{Hemerografía}

Jornal Folha de S. Paulo - Caderno Cotidiano. Junio de 2009-Novembro de 2009Novembro de 2012.

Jornal El Pais. Maio de 2011 e Novembro de 2012-Maio de 2013.

Carla Reis Longhi es graduada em História por la PUC/SP, doctora en Historia por la Universidade de São Paulo. Actualmente es professora titular en el programa de posgrado en Comunicación de la Universidad Paulista y profesora titular en el Centro universitario de Bellas Artes. Dirige el grupo de investigación "Mídia, Cultura e Política: representações, identidades e configurações do público e do privado". 